\title{
Current Scenario of Neonatal Sepsis in West U.P
}

\author{
Gupta L.K. ${ }^{1}$, Dayal R. ${ }^{2}$, Yadav M.B. ${ }^{3}$, Kumar N. ${ }^{4}$, Singh M. ${ }^{5}$ \\ ${ }^{1}$ Dr. L. K. Gupta, Senior Consultant, District Women Hospital, Firozabad, ${ }^{2}$ Dr. R. Dayal, Professor and Head, \\ ${ }^{3}$ Dr. Mukesh Babu Yadav, Assistant Professor, ${ }^{4}$ Dr. Neeraj Kumar, Professor, ${ }^{5}$ Dr. Madhu Singh, Lecturer, ${ }^{2,3,4,5}$ Authors \\ are attached with Department of Pediatrics, S.N. Medical College, Agra, UP, India.
}

Corresponding Author: Dr. Madhu Singh, Lecturer, Department of Pediatrics, S.N. Medical College, Agra. E-mail: drmadhupaeds@gmail.com

\begin{abstract}
Background: Sepsis is a significant cause of morbidity and mortality in neonates. Babies born with weight which is $\leq 2500$ grams and those who are born prematurely are the main victims of neonatal sepsis. Early and prompt diagnosis is very crucial for intact survival. Clinical symptoms alone cannot be taken as a criteria to diagnose neonatal sepsis. Thus, for early diagnosis of neonatal sepsis, in addition to clinical signs and symptoms, a test is required which is easy, affordable and rapid. Materials and Method: A cross sectional study was done between March, 2017 and May, 2018 in the Department of Pediatrics, S.N. Medical College, Agra. Before giving the first shot of antibiotic, blood samples of neonates were obtained by peripheral venous puncture under strict aseptic precautions and were evaluated for serial CReactive protein levels and complete blood counts. Blood culture were sent in all suspected sepsis neonates. Results: Among total 58 suspected sepsis cases, 22 and 36 were females and males respectively; 8 neonates were Extremely Low Birth Weight, 14 were Very Low Birth Weight, 17 were Low Birth Weight \& 19 were of normal birth weight; 38 and 20 neonates were preterm and term respectively; 21 presented within 72 hours of birth while 37 neonates were of Late onset sepsis. C-Reactive Protein were positive in $70.6 \%$ cases initially and $86.2 \%$ cases were positive after 24 hours. 19 were found to be proven culture positive. Conclusion: Serial C-Reactive Protein measurement is a better indicator of neonatal sepsis. In addition to clinical signs and symptoms and presence of neonatal and maternal risk factors, serial C-Reactive Protein should be used to detect early and late neonatal sepsis. Probable sepsis cases should always be confirmed with blood culture.
\end{abstract}

Keywords- ELBW-Extremely Low Birth Weight, PROM- Premature Rupture of Membrane

\section{Introduction}

Sepsis is one of the most common cause of hospitalization and death among newborns occurring within the first 28 days of life after prematurity and birth asphyxia [1]. Epidemiological data extracted from developing countries revealed that there is a significant difference between the incidence, risk factors pattern and antibiotic sensitivity when compared with developed countries.

While Group B streptococcus predominate the microbial flora in term newborns in developed countries, gram negative bacterial predominance is common in developing countries. Early-onset sepsis (EOS) can be defined on the basis of age at onset, with bacteremia, pneumonia and bacterial meningitis occurring within first $72 \mathrm{~h}$ in infants hospitalized in the

Manuscript received: $28^{\text {th }}$ November 2018

Reviewed: $8^{\text {th }}$ December 2018

Author Corrected: $16^{\text {th }}$ December 2018

Accepted for Publication: $20^{\text {th }}$ December 2018 neonatal intensive care unit (NICU), versus $<7$ days in term infants [2-4]. EOS in preterm infants, can be defined as occurring in the first 3 days of birth due to placental transfer of bacterial flora from mother to infant before or during delivery [3]. Late-onset sepsis (LOS) is sepsis occurring after 72 hours, has been variably defined as occurring up to the age of $<90$ or 120 days. Bacterial pathogens can be acquired via placenta or are horizontally acquired [2,3, 5-7]. Viral or fungal infection may also occur at $<7$ days of life and should be distinguished from bacterial sepsis $[8,9]$.

GBS and Escherichia coli, constitute the major flora to cause early-onset neonatal sepsis in both term and preterm infants, together accounting for approximately $70 \%$ of infections. Other organisms which are present in minority of cases, are other streptococci (most commonly viridans group streptococci but also Streptococcus pneumoniae), Enterococcus spp, 


\section{Original Research Article}

Staphylococcus aureus, Gram-negative bacilli such as Enterobacter spp., Haemophilusinfluenzae and Listeria monocytogenes $[10,11,12]$.

Signs and symptoms of clinical neonatal sepsis are found to vary with gestational age of newborn and severity of infection.

A newborn may present with lethargy, hypothermia, and poor feeding. Hypothermia is a much commoner symptom than hyperthermia.

Fever alone is a rare symptom unless the mother was febrile and she developed fever immediately after delivery. Respiratory symptoms are common and may include apnea, tachypnea, nasal flaring, grunting, and intercostal retractions.

Cardiac symptoms includes cyanosis, desaturation, decreased heart rate, poor perfusion, increased capillary refill time, and hypotension. Subtle changes in respiratory pattern of newborns, temperature instability, or refusal to feed can be the first signs of a lifethreatening infection.

Preterm infants often have apnea, bradycardia, and cyanosis as the first sign of infection.

Lim et al. reported a high incidence of "poor activity," presumably lethargy and increased respiratory effort [13].

Infants with sepsis typically present within the first 6 hours after birth, and the majority presenting within the first $24 \mathrm{~h}$ of life.

As the signs and symptoms of neonatal sepsis are nonspecific, other diagnoses such as congenital heart disease, respiratory distress syndrome (RDS), transitory tachypnea of newborns, congenital diaphragmatic hernia, and other congenital lung deformities should be excluded.

Clinical symptoms alone cannot form the basis of diagnosis of neonatal sepsis as they are nonspecific and shared by a multitude of neonatal conditions. Blood Culture is the gold standard for diagnosis but is time consuming and requires expertise.

C- Reactive Protein can be used as a fast and affordable tool to diagnose neonatal sepsis to avoid unnecessary antibiotic administration as the latter can lead to emergence of antibiotic resistance a more fearful event in the coming future.

\section{Materials and Method}

Place and Type of Study: After taking ethical clearance, this cross sectional study was carried out in Tertiary Care Hospital in Agra and Firozabad from March, 2017 to May, 2018. An informed consent was taken from the guardian of each newborn prior to the enrolment in our study.

Sample collection and Sample size (n): A total of 58 neonates were included in our study. We evaluated our neonates keeping in mind both nonspecific and specific features of sepsis.

All suspected neonatal cases were investigated for blood culture to confirm the diagnosis of neonatal sepsis. Samples for blood culture were taken from peripheral veins under strict aseptic precautions.

Before administrating the first dose of antibiotic, around $4 \mathrm{ml}$ blood was withdrawn out of which $1 \mathrm{ml}$ for a term infant and $0.5 \mathrm{ml}$ for preterm infant was transferred in enriched soybean plus casein broth media (BACTEC PD vial) and send immediately for detection of bacterial and fungal growth and to evaluate the antibiotic sensitivity pattern.

$1 \mathrm{ml}$ of the total sample withdrawn was sent for CRP test which is done by rapid latex agglutination method using the diagnostic kit.

Around $1 \mathrm{ml}$ of the sample was sent for complete blood count which included hemoglobin, total leucocyte count, differential leucocyte count and platelet count.

The rest $1 \mathrm{ml}$ was used to evaluate Absolute neutrophil count, band cells and Immature to total leucocyte ratio (I/T ratio). According to criteria of Manroe et al and Lloyd et al, TLC $<5000 / \mathrm{mm} 3$, ANC $<1800 / \mathrm{mm} 3$, I $/ \mathrm{T}$ ratio $>20 \%$ were defined as abnormal.

Inclusion Criteria: All the neonates with clinical features of sepsis in the study period. The clinical criteria taken as indicative of sepsis was presence of signs and symptoms and /or two risk factors.

a) Maternal risk factor: Fever within 2 weeks prior to delivery, prolonged rupture of membrane $>18$ hours, foul smelling and/or meconium stained liquor, single unclean or $>3$ sterile vaginal examinations during labour, prolonged labour( Sum of first and second stage of labour $>24$ hours)

b) Neonatal risk factor: Low Birth Weight, prematurity. 


\section{Original Research Article}

Signs and symptoms of Sepsis: Refusal to feed, feeding intolerance, lethargy, excess irritability, high pitched cry, seizures, hypotonia, temperature instability, apnea, respiratory distress, poor perfusion, tachypnea, bradycardia, abdominal distension, necrotizing enterocolitis, vomiting, sclerema, mucosal bleeding.

\section{Results}

Among total 58 suspected sepsis cases, 36 were males \& 22 were females; 08 were Extremely low birth weight, 14 were Very Low Birth Weight, 17 were LBW \& 19 were $\geq 2.5$ birth weight; 38 were preterm \& 20 were term; 21 were EOS \& 37 were LOS [Table -1].

Table-1: The Clinical and Demographic Profile of Neonates with Neonatal Sepsis is as follows:

\begin{tabular}{|c|c|}
\hline \multicolumn{2}{|c|}{ Gender profile of study population } \\
\hline Females & 22 \\
\hline Male & 36 \\
\hline \multicolumn{2}{|c|}{ Gestational age profile of study population } \\
\hline Preterm $(<37$ Weeks $)$ & 38 \\
\hline Term $(370 / 7-416 / 7)$ & 20 \\
\hline \multicolumn{2}{|c|}{ Birth weight profile of study population } \\
\hline Extremely Low Birth Weight & 08 \\
\hline Very Low Birth Weight & 14 \\
\hline Low Birth Weight & 17 \\
\hline Normal Birth Weight & 19 \\
\hline \multicolumn{2}{|c|}{ Distribution of sepsis cases according to the onset of sepsis } \\
\hline EOS $(<72$ Hours $)$ & 21 \\
\hline $\operatorname{LOS}(\geq 72$ Hours $)$ & 37 \\
\hline
\end{tabular}

According to our study males were more affected by neonatal sepsis when compared with females. Prematurity and LBW are significantly associated with neonatal sepsis.

Out of 58 neonates, 37 neonates presented after 72 hours of life with signs and symptoms suggestive of Neonatal sepsis. 
Table-2: Distribution of cases according to maternal risk factors and comparison between the EOS and LOS is provide in the table below:

\begin{tabular}{|c|c|c|}
\hline EOS & \multicolumn{2}{|c|}{ LOS } \\
\hline \multicolumn{3}{|l|}{ Mode of Delivery } \\
\hline Normal Vaginal Route & 13 & 20 \\
\hline LSCS & 8 & 17 \\
\hline \multicolumn{3}{|l|}{ Place of Delivery } \\
\hline Home & 7 & 12 \\
\hline Institutional & 14 & 25 \\
\hline \multicolumn{3}{|l|}{ Maternal Fever } \\
\hline Yes & 4 & 8 \\
\hline No & 17 & 29 \\
\hline \multicolumn{3}{|c|}{ Meconium Stained Liquor } \\
\hline Yes & 4 & 7 \\
\hline No & 17 & 30 \\
\hline \multicolumn{3}{|l|}{ PROM(>18 Hours) } \\
\hline Yes & 3 & 6 \\
\hline No & 18 & 31 \\
\hline \multicolumn{3}{|c|}{ Prolonged Labour ( $>24$ Hours) } \\
\hline Yes & 2 & 6 \\
\hline No & 19 & 31 \\
\hline \multicolumn{3}{|l|}{ Foul Smelling Liquor } \\
\hline Yes & 07 & 4 \\
\hline No & 14 & 33 \\
\hline \multicolumn{3}{|c|}{ Multiple PV Examinations } \\
\hline Yes & 3 & 8 \\
\hline No & 18 & 29 \\
\hline
\end{tabular}

In 21 neonates who presented as EOS, 13 were born by NVD as compared to 8 delivered by LSCS. Maternal fever and meconium staining was present in 4 each, out of 21 newborns with EOS. In newborn with LOS maternal fever and meconium staining were present is 8 and 7 newborns respectively. Maternal history of prolonged labour was present in 6 out of 31 LOS cases. Multiple PV examinations and foul smelling liquor was present in 4 and 8 newborns respectively in LOS cases. 
Table- 3: Frequency Distribution of patient group according to result of CRP is tabulated as below:

\begin{tabular}{|c|c|c|}
\hline & $\begin{array}{c}\text { At The Time Appearance Of Clinical } \\
\text { Symptoms (\%) }\end{array}$ & After 24 Hours Of First Sample (\%) \\
\hline CRP Positive & $41(70.68 \%)$ & $50(86.20 \%)$ \\
\hline CRP Negative & 17 & 8 \\
\hline
\end{tabular}

CRP was positive in $41(70.6 \%)$ out of 58 cases and on repeat levels after 24 hours of the first sample the value were positive in 50 cases constituting nearly $86.2 \%$. 17 cases were CRP negative at the time of first sample and 9 cases who were CRP positive initially were found CRP positive on serial measurement.

Table-4: Frequency Distribution of patient group according to results of blood culture is as described under:

\begin{tabular}{|l|c|c|}
\hline Blood Culture Result & Number & Percentage \\
\hline Staphylococcus & 5 & 8.62 \\
\hline Klebsiella & 5 & 1.72 \\
\hline Streptococcus & 1 & 1.72 \\
\hline Acinetobacter & 1 & 1.72 \\
\hline E-Coli & 1 & 6.89 \\
\hline Candida & 4 & 1.72 \\
\hline Candida + Staphyloccus & 1 & 1.72 \\
\hline Klebsiella + Candida & 1 & 67.2 \\
\hline No Growth & 39 & $\mathbf{1 0 0}$ \\
\hline Total & $\mathbf{5 8}$ & \\
\hline
\end{tabular}

Out of the total 58 neonates screened for neonatal sepsis, 19 cases were proven culture positive. Staphylocoocus and Klebsiella scored the highest number ( 5 each) accounting nearly $8.62 \%$ out of total cases. Candida closely followed the above two organisms accounting for nearly 6.89\%. Mixed infection with Candida and Staphylococcus/ Klebsiella was also detected in 2 cases. Other species detected were Streptococcus, E.Coli and Acinetobacter.

Out of 58 neonates, 31 were born by normal vaginal route and 27 were born by Lower Segment Cesarean Section. Out of 58 deliveries 10 were at home while 48 deliveries were done at institution. Premature rupture was present in 15 and multiple per vaginal examinations was done in 16 mothers out of 58 mothers. Meconium stained liquor was present in 19 out of 58 mothers. 13 out of 58 gave the history of fever within 2 weeks prior to delivery . Foul smelling liquor was found in 09 mothers [Table-2].

CRP was done at the time of appearance of clinical symptoms and after 24 hours of the first sample $70.6 \%$ neonates were CRP positive at the time of first appearance of clinical symptoms of sepsis while $86.20 \%$ neonates were found CRP positive after 24 hours of first sample [Table-3].

According to the blood culture report, patients were divided into two subgroups:-

Proven sepsis group:- included 19 patients who had positive blood culture report.

Probable sepsis group:- included 39 patients who had sterile blood culture report. 
Blood cultures were positive in only $32.75 \%$ cases. Staphylococcus aureusand Klebsielia ( $8.6 \%$ each) were the most common causative organism of sepsis followed by Candida (6.8 \%), Streptococcus (1.72\%), Acinetobacter (1.72\%) and E. coli (1.72\%).

Mixed infections with Candida and Staphylococcus was present in 1 neonate (1.72\%). Candida and Klebsiella coinfection was present in 1 nonate during the study period [Table-4].

\section{Discussion}

Neonatal sepsis is a clinical syndrome which is characterized by signs and symptoms of infection with or without bacteremia in the first month of life [14].

The spectrum of neonatal sepsis is very wide including varied presentation like septicemia, pneumonia, bacterial meningitis, arthritis, osteomyelitis, urinary tract infections etc.

Worldwide, the incidence of neonatal sepsis has came down to $\leq 1$ case per thousand live births owing to intrapartum antibiotic prophylaxis (IAP). Highest number of cases occurs among very low birth weight infants with a incidence of $10-15$ cases/ 1000 VLBW births.

According to National Neonatal Perinatal Database (2002-03), sepsis contributed to nearly $19 \%$ of all neonatal deaths.

Prematurity predisposes to bacterial sepsis. The incidence of neonatal sepsis is very high in infants with birth weight less than 1000 grams constituting nearly 26 per thousand live births when compared to 8-9 per thousand live births in babies with birth weight between 1000-2000 grams. The risk of death due to meningitis is also higher in infants born with a birth weight lesser than 2500 grams.

Various factors were found to be associated with neonatal sepsis. The presence of these risk factors warrants an early diagnosis and treatment to save the life of the newborn. Low birth weight and prematurity were mainly associated with neonatal sepsis [15].

Betty et al reported that nearly $80 \%$ of preterm babies in their study group developed sepsis. Other determinants were febrile illness in mother 2 weeks prior to delivery, foul smelling liquor, meconium staining of liquor, prolonged rupture of membranes or prolonged labour, multiple vaginal examinations etc [16].

Tallur et al and Raghvan et al evaluated neonates and found that birth asphyxia is a potent risk factor for neonatal sepsis $[17,18]$. Tallur et al also reported that male babies are much prone to neonatal sepsis than females [17]. Raghvan et al studied the maternal risk factor association with neonatal sepsis and came to conclusion that foul smelling liquor, meconium staining and prolonged labour are significantly assosciated with neonatal sepsis [18].

Blood Culture still remain the gold standard for confirming the diagnosis of neonatal sepsis. The success of isolating a bacteria from a blood sample depends on the volume of blood culture, timing and frequency of culture, duration and dilution of culture media and the choice of the culture system [19].

Schelonka et al found that if organisms are present at densities of $<4 \mathrm{CFU}$, blood volume of $0.5 \mathrm{ml}$ or less had a significantly diminished chance of detecting bacteremia [20]. In our study $32.75 \%$ cases were culture positive, with equal incidence of both gram positive and gram negative organisms.

Highest percentage was shared by both Staphylococcus and Klebsiella (5 out of total 19 culture positive cases; $26.3 \%$ ) in our study closely followed by Candidal infection.

Simlar results were found in the work of Karthikeyan et al and Kumhar et al who individually demonstrated that Staphylococcus and Klebsiella are the most common organism detected in culture positive cases [21,22]. Similar to our results, R. Rani et al studied 444 blood samples of clinically diagnosed septicemic neonates and out of 144 culture positive samples, 50 (34.7\%) were Candida isolates [23].

CRP was found to be positive in almost $70.68 \%$ neonates in our study closely resembling the results of W.E Benitz et al and E. Hisamuddin et al [24,25]. Blood samples were again taken considering all aseptic precaution after 24 hours of first sample which converted into $86.20 \%$ positivity.

The serial rise of CRP levels were found to be a better indicator of neonatal sepsis than a single value alone. $\mathrm{N}$. Hofer et al found that CRP has the best diagnostic 
accuracy when combined with another infection marker and provides reliable sensitivity during the early phases of sepsis [26].

A wide variety of markers has been studied including presepsin, procalcitonin, interleukin- 6 etc to detect early neonatal sepsis.

These parameters may provide similar results as CRP but before being used as a definitive marker extensive research on large population is required. CRP is certainly the most affordable, most studied and most used test to detect early neonatal sepsis and therefore the best parameter we have to start empirical treatment before the blood culture report confirms the organisms.

Serial blood levels further potentiate its specificity in the diagnosis of neonatal sepsis.

\section{Conclusion}

Low birth weight and prematurity were the most important determinant of neonatal sepsis. Male neonates were found to be affected more than females. Maternal risk factors like foul smelling liquor, fever, prolonged labor, multiple per vaginal examinations and premature rupture of membranes are also associated with neonatal sepsis. Blood culture is the gold standard for diagnosis of neonatal sepsis. Staphylococcus and Klebsiella are the most common organism closely followed by Candida. Mixed infections with Candida and other bacteria were also detected. Serial CRP measurement revealed increasing sensitivity after 24 hours.

Serial CRP measurement in addition to clinical signs and symptoms and a consideration of neonatal and maternal risk factors should be used to detect early and late neonatal sepsis. Probable sepsis cases should always be confirmed with blood culture.

\section{Declaration}

Funding: Nil, Conflict of interest: None initiated, Perission from IRB: Yes

\section{References}

1. Edwards MS, Baker CJ. Sepsis in the newborn. Krugman's Infectious Diseases of Children.2004, 11th ed. Philadelphia, PA: Mosby: 545.

2. Schuchat A. Neonatal group B streptococcal disease-screening and prevention. N Engl J Med. 2000 Jul 20; 343(3):209-10. DOI:10.1056/NEJM200007203430310
Original Research Article

3. Hornik CP, Fort P, Clark RH, et al. Early and late onset sepsis in very-low-birth-weight infants from a large group of neonatal intensive care units. Early Hum Dev. 2012 May;88 Suppl 2:S69-74. doi: 10.1016/ S03 78-3782(12)70019-1.

4. Edwards MS, Gonik B. Preventing the broad spectrum of perinatal morbidity and mortality through group B streptococcal vaccination. Vaccine. 2013 Aug 28; 31 Suppl 4:D66-71. doi: 10.1016/j.vaccine. 2012. 11.046. Epub 2012 Nov 28.

5. Franciosi RA, Knostman JD, Zimmerman RA. Group B streptococcal neonatal and infant infections. J Pediatr. 1973 Apr;82(4):707-18.

6. Bauserman MS, Laughon MM, Hornik CP, et al. Group B Streptococcus and Escherichia coli infections in the intensive care nursery in the era of intrapartum antibiotic prophylaxis. Pediatr Infect Dis J. 2013 Mar; 32 (3):208-12. doi: 10.1097/INF.0b013e 3182750 $58 \mathrm{a}$.

7. Guilbert J, Levy C, Cohen R; et al. Late and ultra late onset Streptococcus B meningitis: clinical and bacteriological data over 6 years in France. Acta Paediatr. 2010 Jan; 99 (1):47-51. doi: 10.1111/j.16512227. 2009.01510.x.

8. Lin TY, Kao HT, Hsieh SH, et al. Neonatal enterovirus infections: emphasis on risk factors of severe and fatal infections. Pediatr Infect Dis J. 2003 Oct; 22(10): 889-94.DOI:10.1097/01.inf.00000 91294. 63706.f3

9. Stoll BJ, Hansen N, Fanaroff AA, et al. Changes in pathogens causing early-onset sepsis in very-low-birthweight infants. N Engl J Med. 2002 Jul 25;347(4): 2407. DOI:10.1056/NEJMoa012657.

10. Hoffman JA, Mason EO, Schutze GE, et al. Streptococcus pneumoniae infections in the neonate. Pediatrics. 2003 Nov;112(5):1095-102.

11. Bizzarro MJ, Raskind C, Baltimore RS, et al. Seventy-five years of neonatal sepsis at Yale: 19282003. Pediatrics. 2005 Sep;116(3):595-602. DOI:10. 1542 /peds.2005-0552

12. Stoll BJ, Gordon T, Korones SB, et al. Late-onset sepsis in very low birth weight neonates: a report from the National Institute of Child Health and Human Development Neonatal Research Network. J Pediatr. $1996 \mathrm{Jul} ; 129(1): 63-71$. 
Original Research Article

13. Lim WH, Lien R, Huang YC, et al. Prevalence and pathogen distribution of neonatal sepsis among verylow-birth-weight infants. Pediatr Neonatol. 2012 Aug; 53 (4):228-34. doi:10.1016/j.pedneo.2012.06.003. Epub 2012 Jul 23.

14. Mussap M, Noto A, Cibecchini F, et al. The importance of biomarkers in neonatology. Semin Fetal Neonatal Med. 2013 Feb;18(1):56-64. doi: 10. 1016 /j. siny.2012.10.006. Epub 2012 Nov 17.

15. Aggarwal R, Sarkar N, Deorari AK, et al. Sepsis in the newborn. Indian J Pediatr. 2001 Dec;68(12):1143-7.

16. Chacko B, Sohi I. Early onset neonatal sepsis. Indian J Pediatr. 2005 Jan;72(1):23-6.

17. Tallur SS, Kasturi AV, Nadgir SD, et al. Clinicobacteriological study of neonatal septicemia in Hubli. Indian J Pediatr. 2000 Mar;67(3):169-74.

18. Raghavan M, Mondal GP, Bhat BV, et al. Perinatal risk factors in neonatal infections. Indian $\mathrm{J}$ Pediatr. 1992 May-Jun;59(3):335-40.

19. Chiesa C, Panero A, Osborn JF, et al. Diagnosis of neonatal sepsis: a clinical and laboratory challenge. Clin Chem. 2004 Feb; 50 (2):279-87. DOI:10.1373/ clinchem. 2003.025171
20. Schelonka RL, Chai MK, Yoder BA, et al. Volume of blood required to detect common neonatal pathogens. J Pediatr. 1996 Aug;129(2):275-8.

21. Karthikeyan G, Premkumar K. Neonatal sepsis: Staphylococcus aureus as the predominant pathogen. Indian J Pediatr. 2001 Aug;68(8):715-7.

22. Kumhar GD, Ramachandran VG, Gupta P. Bacteriological analysis of blood culture isolates from neonates in a tertiary care hospital in India. J Health Popul Nutr. 2002 Dec;20(4):343-7.

23. Rani R, Mohapatra NP, Mehta G, Randhawa VS. Changing trends of Candida species in neonatal septicemia in a tertiary north Indian hospital. Indian $\mathrm{J}$ Med Microbiol. 2002; 20(1):42-4.

24. Benitz WE, Han MY, Madan A, et al. Serial serum $\mathrm{C}$-reactive protein levels in the diagnosis of neonatal infection. Pediatrics. 1998 Oct;102(4):E41.

25. Hisamuddin E, Hisam A, Wahid S, et al. Validity of C-reactive protein (CRP) for diagnosis of neonatal sepsis. Pak J Med Sci. 2015;31(3):527-31. doi: 10. 12669 / pjms. 313.6668 .

26. Hofer N, Zacharias E, Müller W, et al. An update on the use of C-reactive protein in early-onset neonatal sepsis: current insights and new tasks. Neonatology. 2012; 102(1):25-36. doi: 10.1159/000336629. Epub 2012 Apr 11.

\section{How to cite this article?}

Gupta L.K, Dayal R, Yadav M.B, Kumar N, Singh M. Current Scenario of Neonatal Sepsis in West U.P. Int J Pediatr Res. 2018;5(12):609-616.doi:10.17511/ijpr.2018.i12.02. 